\title{
Theoretical And Actual Bearing Capacity Of Driven Piles Using Model Piles In Sand
}

\author{
Wong Kok Leong ${ }^{1,}$, , Nor Azizi Yusoff ${ }^{2, b}$, Ameer Nazrin Abd Aziz ${ }^{3, c}$, \\ Zaihasra Abu Talib ${ }^{4, d}$ \\ 1, 2, 3, 4 Faculty of Civil and Environmental Engineering \\ Universiti Tun Hussein Onn Malaysia, Malaysia
}

\begin{abstract}
leowong87@gmail.comª, azizy@uthm.edu.my ${ }^{\mathrm{b}}$, ameernazrinaziz@yahoo.comc, zaihasra@uthm.edu.my ${ }^{\mathrm{d}}$
\end{abstract}

\begin{abstract}
Keywords: Actual Pile Bearing Capacity, Theoretical Pile Bearing Capacity, Rate of Penetration, cohesionless soil, pile test model
\end{abstract}

\begin{abstract}
In general, increasing of penetration rate may result in an increased of pile capacity. Occasionally, there were differences between theoretical and actual bearing capacity of the piles. Rate of penetration of pile influenced the pile bearing capacity. The bearing capacity of model pile increased as the rate of loading increased based on pile driving formula. Therefore, the study was conducted to determine the bearing capacity of model piles with different penetration forces based on theoretical method and experimented analysis. Five circular hollow section model piles using pipe pile were used to penetrate into cohesionless soil with different penetration force respectively. The loading for ultimate bearing capacity using theoretical calculation was approximately about $0.163 \mathrm{kN}$. However, referring to the limitation of a laboratory setup, the maximum loading was $0.12 \mathrm{kN}$. Several trials had been initiated but when it reached $0.14 \mathrm{kN}$, the setup was unstable and dangerous to be continued. Therefore, the ultimate bearing capacity derived by the pile load test results were based on a pile moved up to $10 \%$ of its tip diameter criteria. In the future, both theoretical and actual calculation must be made to avoid any confusion and detect mistakes in near future
\end{abstract}

\section{Introduction}

Deep foundation such as piles was a solution for engineers because piles transfers load exerted by structure on the ground surface to the deeper soil layer [1].Bearing capacity refers to the capacity of soil to support the loads applied to the ground [1], [2]. There were a few criteria that needs to be considered during the designing work such as the ultimate bearing capacity of foundations. In general, increasing the load rate results an increase of the pile capacity. It is important to investigate and determine the bearing capacity of piles with different penetration forces on soil so friction pile can be applied on site. The result from the penetration and pile load test could be use to determine the ultimate bearing capacity of piles. The results later were compared with the theoretical formula and pile driving formula. The loading rate effect on piles in clay from laboratory model tests showed that the loading rate has a significant influence on both the compressive and the uplift capacity of the model pile [3].

\section{Model Pile Driving Setup}

The pile load test is one of the direct methods for determining the allowable load on piles which useful for determining the bearing capacity of cohesionless soils. However, in case of cohesive soils, the data from the pile load test should be used with caution on account of disturbance due to pile driving, development of pore pressure, and the inadequate time allowed for consolidation settlement. Among the best way to access the load that carries capacity of a pile was by using pile load test [4]. The pile was loaded to a designated loading for developing load-settlement curve. 
From the curve, allowable load can be obtained. The pile load test setup for this study was as shown in Figure 1 and 2.

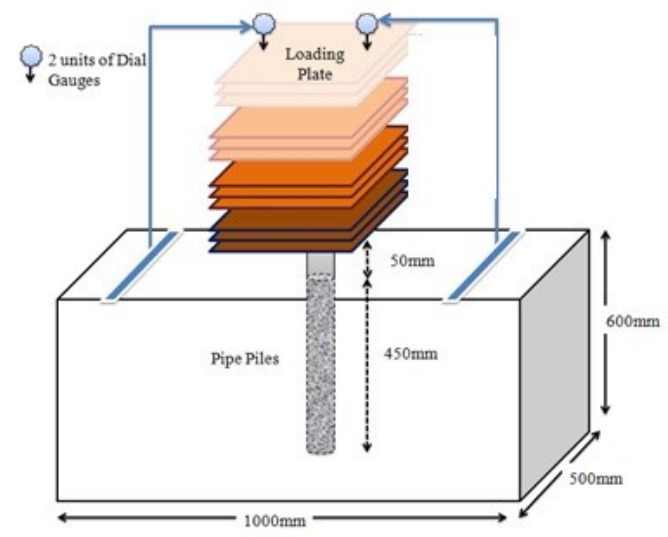

Fig. 1 Pile load test setup

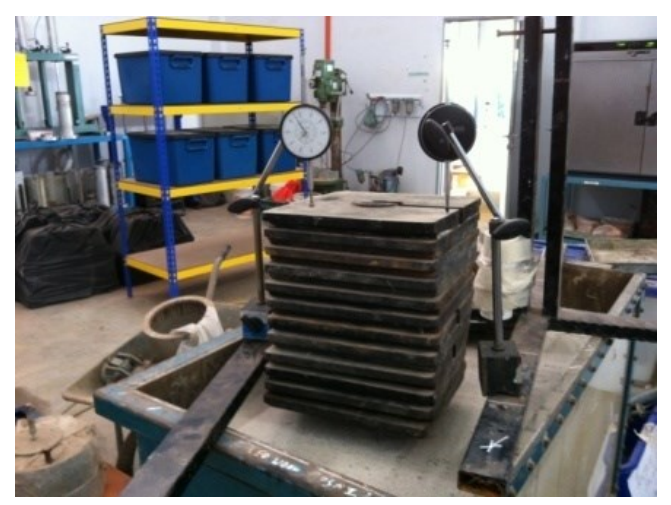

Fig. 2 Pile load test model

\section{Meyerhof's Method}

Meyerhof's formula was used to determine the ultimate point as follows:

$$
\begin{aligned}
& \mathrm{Q}_{\mathrm{p}}=\mathrm{A}_{\mathrm{p}} \mathrm{q}_{\mathrm{p}}=\mathrm{A}_{\mathrm{p}} \mathrm{q}^{\prime} \mathrm{N}_{\mathrm{q}}^{\prime} \\
& \mathrm{A}_{\mathrm{p}}=\pi \mathrm{D}^{2} \\
& \mathrm{~A}_{\mathrm{p}}=\frac{\pi D^{2}}{4}=\frac{\pi 0.0254^{2}}{4}=0.000507 \mathrm{~mm}^{2} \\
& \mathrm{q}^{\prime}=\gamma L=(1736.11 \times 9.81) \times 0.5=8.52 \mathrm{KN} / \mathrm{m}^{2}
\end{aligned}
$$

When $\varnothing^{\prime}=23, N^{\prime} q=17.9$

$$
\begin{aligned}
& \mathrm{Q}_{\mathrm{p}}=0.000507 \times 8.52 \times 17.9 \\
& \mathrm{Q}_{\mathrm{p}}=0.077 \mathrm{KN}
\end{aligned}
$$




\section{Frictional Resistance $\left(Q_{s}\right)$ in Sand}

To get the theoretical ultimate bearing capacity, friction resistance of the pile in sand needed to be calculated as follows. Two equations were used to get a presentable frictional resistance. Table 1 shows the detail of frictional resistance calculation.

Table 1 Detail for frictional resistance calculation

\begin{tabular}{lr}
\hline Critical depth, $\mathrm{L}^{\prime}(\mathrm{m})$ & 0.381 \\
\hline Effective earth pressure coefficient, K & 1.26 \\
Effective vertical stress at the depth under consideration, $\sigma^{\prime} \mathrm{o}$ & 6.49 \\
$\left(\mathrm{KN} / \mathrm{m}^{2}\right)$ & \\
Soil-pile friction angle at $0.381 \mathrm{~m}, \delta^{\prime}$ & 22.4 \\
Length of the pile, L (m) & 0.5 \\
Perimeter of pile, $\mathrm{p}(\mathrm{m})$ & 0.008 \\
\hline
\end{tabular}

$$
f=K \sigma^{\prime}{ }_{0} \tan \delta^{\prime \prime}
$$

At $\mathrm{Z}=0 \mathrm{~m}, \mathrm{f}=0$

At $\mathrm{Z}=0.381 \mathrm{~m}$,

$$
\begin{aligned}
& f=1.26(6.49) \tan 22.4 \\
& f=3.37 \mathrm{KN} / \mathrm{m}^{3}
\end{aligned}
$$

Frictional Resistance using equation 1,

$$
\begin{aligned}
& Q_{s}=\frac{f_{z=0}+f_{z=0.381}}{2} p L^{\prime}+f_{z=0.381} p\left(L-L^{\prime}\right) \\
& Q_{s}=\frac{0+3.37}{2} 0.08(0.381)+3.37(0.08)(0.5-0.381) \\
& Q_{s}=0.0834 \mathrm{KN}
\end{aligned}
$$

Frictional Resistance using equation 2,

Effective Vertical stress at the depth under consideration, $\sigma^{\prime} \mathrm{o}=4.26 \mathrm{KN} / \mathrm{m}^{2}$

$$
\begin{aligned}
Q_{s} & =K \sigma^{\prime}{ }_{o} \tan \left(\delta^{\prime}\right) p L \\
Q_{s} & =1.26(4.26) \tan (22.4)(0.08)(0.5) \\
Q_{s} & =0.0885 K N
\end{aligned}
$$

Average Frictional Resistance,

$$
\begin{aligned}
& Q_{s(\text { ave })}=\frac{0.0834+0.0885}{2} \\
& Q_{s(\text { ave })}=0.086 \mathrm{KN}
\end{aligned}
$$




\section{Theoretical Ultimate Bearing Capacity}

$$
\begin{gathered}
\mathrm{Q}_{\mathrm{u}}=\mathrm{Q}_{\mathrm{p}}+\mathrm{Q}_{\mathrm{s}} \\
\mathrm{Q}_{\mathrm{u}}=0.077+0.086 \\
\mathrm{Q}_{\mathrm{u}}=0.163 \mathrm{KN} 1
\end{gathered}
$$

The value of the ultimate bearing capacity by using the theoretical formula is $0.163 \mathrm{KN}(\mathbf{1 6 . 3 K g})$.

\section{Results of Pile Driving}

Based on the result, the typical pile load test settlement curves were shown in Figure 3. All the test results showed similar behaviour when the loading plate and settlement to the sand was increased. A review of the pile load test curves for all tests indicated the settlement does not show peak behaviour with the increasing of the loading plate. Therefore, the failure loads was evaluated using the pile head which moved $10 \%$ of the pile tip diameter method $[5,6,7]$. By referring to the method, the bearing capacity was taken as the corresponding $10 \%$ pile diameter. The Results of the $10 \%$ pile diameter are shown in Table 2 and Figure 4.

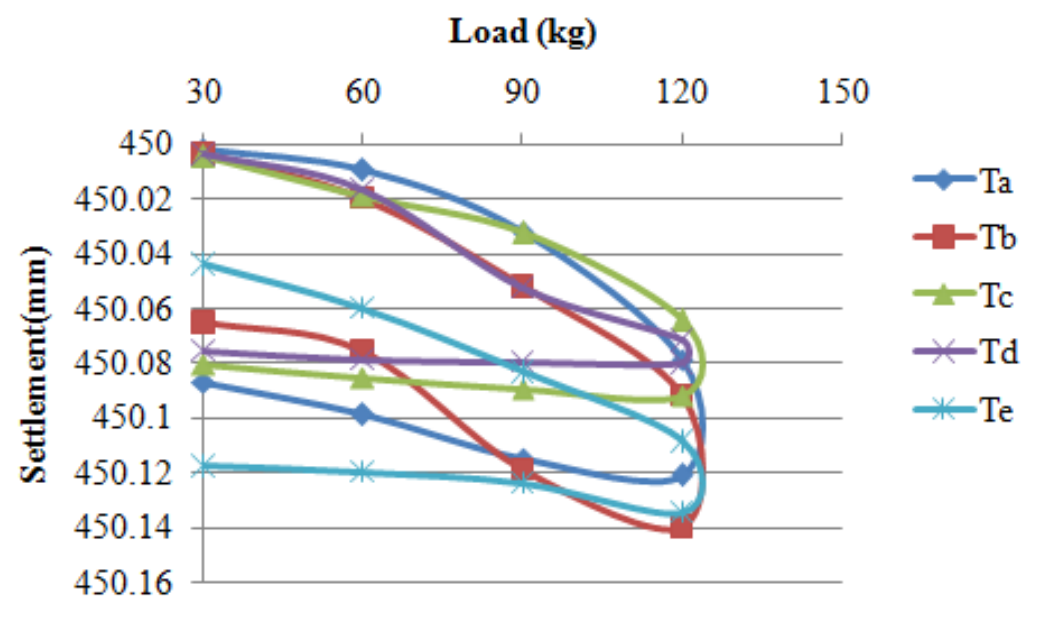

Fig. 3 Load Versus Settlement Curve for all tests

Table 2 Ultimate bearing capacity for corresponding $10 \%$ pile diameter

\begin{tabular}{cccccc}
\hline $\begin{array}{c}\text { Drop } \\
\text { Height }\end{array}$ & $\begin{array}{c}50 \mathrm{~mm}, \\
\mathrm{Ta}\end{array}$ & $\begin{array}{c}150 \mathrm{~mm}, \\
\mathrm{~Tb}\end{array}$ & $\begin{array}{c}200 \mathrm{~mm}, \\
\mathrm{Tc}\end{array}$ & $\begin{array}{c}250 \mathrm{~mm}, \\
\mathrm{Td}\end{array}$ & $\begin{array}{c}300 \mathrm{~mm}, \\
\mathrm{Te}\end{array}$ \\
\hline $\mathrm{Q}_{\mathrm{u}}(\mathrm{kN})$ & 0.52 & 0.62 & 0.72 & 1.04 & 0.92 \\
& & & & & \\
\hline
\end{tabular}




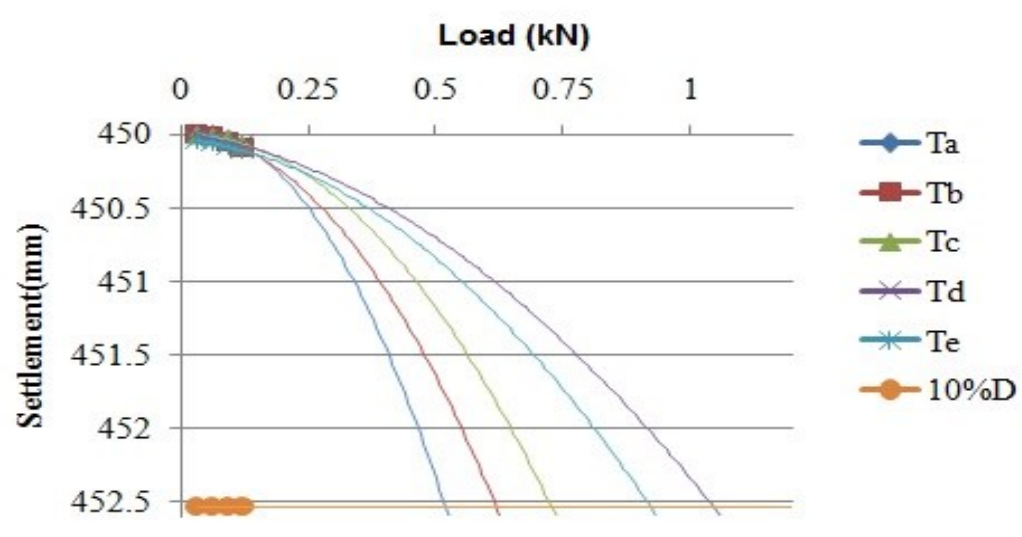

Fig. 4 Ultimate bearing capacity for corresponding $10 \%$ pile diameter movement

\section{Differences Between Theoretical and Load Test Ultimate Pile Bearing Capacity $\left(Q_{u}\right)$}

Comparison between ultimate bearing capacities from interpretation of load test results and theoretical method (Meyerhof's formula) shows the percentages differences ranging from 219\% up to $539 \%$ (Table 3). The theoretical formula used the Meyerhof's formulas only considered at the model properties only. Meanwhile, the actual pile load test refers to the actual situation at the laboratory test. Figure 5 shows the comparison between ultimate bearing capacities of theoretical and load test results. During the laboratory testing, the maximum load test had been carried out was $0.12 \mathrm{kN}$. Meanwhile, based on the theoretical calculation by using Meyerhof's, it was estimated up to $0.16 \mathrm{kN}$. In a laboratory, the test should be carried out up to two times the design load. However, due to safety precaution, it is difficult to conduct the test up to the designated loading condition. During the test, the loading plate was slightly unstable when the load reached $0.14 \mathrm{kN}$. Hence, safety precautions need to be considered during the laboratory tests. Therefore, the safety frame should be prepared to prevent the pile load test from failing.

Table 3 Comparison between ultimate bearing capacity of theoretical and actual load test results

\begin{tabular}{|c|c|c|c|}
\hline \multirow{2}{*}{$\begin{array}{c}\text { Drop Height } \\
(\mathrm{mm})\end{array}$} & \multicolumn{3}{|c|}{ Bearing Capacity $(\mathrm{kN})$} \\
\cline { 2 - 4 } & Theoretical & \multicolumn{2}{|c|}{ Pile Load Test } \\
\cline { 2 - 4 } & Meyerhof's & $10 \% \mathrm{D}$ & $\begin{array}{c}\text { Diff } \\
(\%)\end{array}$ \\
\hline $50, \mathrm{Ta}$ & 0.163 & 0.52 & -219.02 \\
\hline $150, \mathrm{~Tb}$ & 0.163 & 0.62 & -280.37 \\
\hline $200, \mathrm{Tc}$ & 0.163 & 0.72 & -341.72 \\
\hline $250, \mathrm{Td}$ & 0.163 & 1.04 & -538.04 \\
\hline $300, \mathrm{Te}$ & 0.163 & 0.92 & -464.42 \\
\hline
\end{tabular}




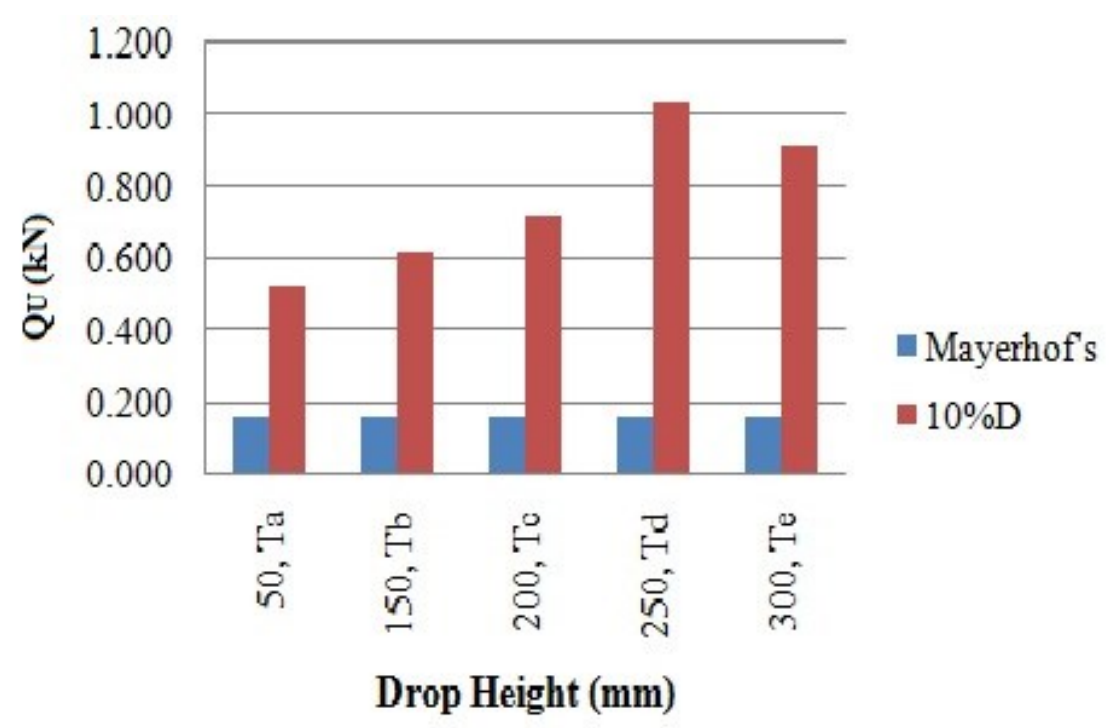

Fig. 5 Comparison of theoretical and actual ultimate bearing capacity

\section{Conclusion}

The results obtained from the analysis enabled a platform for comparison between the Theoretical method (Meyerhof's formula) results and Pile Load Test results (failure criteria $10 \%$ of the pile tip diameter).

From the data analysis, the following conclusions can be derived:

1. The ultimate bearing capacity using theoretical calculation is approximately up to $0.163 \mathrm{kN}$. However, referring to the limitation of a laboratory setup, the maximum loading was $0.120 \mathrm{kN}$. Several trials had been initiated but when it reached $0.140 \mathrm{kN}$, the setup was unstable and could be dangerous to be conducted.

2. The ultimate bearing capacity derived by a pile load test results are based on when a pile moved $10 \%$ of its tip diameter $[5,6,7]$.

3. The actual load-settlement curves were not reaching the failure criteria of the maximum loadings. Therefore, the larger loads should be applied in the future in order to obtain a better understanding.

\section{Recommendation}

This study focuses on the comparison of the results of between theoretical analysis, pile driving formulas and pile load test. In the future, more studies may be conducted with the following criteria:

1. Pile load must carry out up to two times of the ultimate bearing capacity theoretical calculations.

2. Pile load test at the laboratory must be safely set up and allow the loading plate to stand properly.

3. To determine bearing capacity of a pile at site, both theoretical and actual calculation must be made to avoid any confusion and detect mistakes in near future.

\section{Acknowledgement}

The author would like to thank his family and friends for their support throughout completing the paper. In addition, the author also expressed his gratitude towards his supervisor, Dr Nor Azizi bin Yusoff for showing guidelines and supports upon completing this paper. Last but not least, thank you to all technicians in RECESS laboratory. Without them, the paper could not be done and complete. 


\section{References}

[1] U.C. Kalita: Soil Mechanics \& Foundation Engineering. Eastern Economy ed. Asoke K. Ghosh, PHI Learning Private Limited, New Delhi. (2011) p. 178-194

[2] B.M. Das: Principles of Foundation Engineering. $7^{\text {th }}$ ed (2011)

[3] A.I. Al-Mhaidib: Experimental investigation of the behaviour of pile groups in sand under different loading rates. Geotechnical and Geological Engineering (2006) p. 889-902

[4] ASTM Standard Method of Testing Piles under Axial Compressive Load (D1143-87). In 1994 Annual Book of ASTM Standards, Sect. 4, Vol. 04.08, ASTM, Philadelphia.

[5] E. Uncuoglu, M. Laman: Lateral Resistance of a Short Rigid Pile In a Two -Layer Cohesionless Soil. Eriyes University and Osmaniye Korkut Ata University. Turkey (2011)

[6] V.A. Vesic: "Design of Pile Foundation, National Cooperative Highway Research Program," Synthesis of Highway Practice No. 42, Transportation Research Board, Washington, D.C. (1977)

[7] A.J. Weltman: "Pile Load Testing Procedure." Report PG7, Construction Industry Research and Information Association (CTJUA). London (1980) 